\title{
EL CONCEPTO LEGAL DE EMPRESA Y EL DERECHO LABORAL: CÓMO SALIR DEL LABERINTO
}

\section{THE LEGAL CONCEPT OF BUSINESS}

AND LABOR LAW:

HOW TO GET OUT OF THE MAZE

\section{LE CONCEPT JURIDIQUE D'ENTREPRISE DANS LE DROIT DU TRAVAIL CHILIEN: LE LABYRINTHE ET SON ISSUE}

José Luis Ugarte Cataldo*

\section{RESUMEN}

A casi una década de iniciada la discusión sobre el concepto de empresa en material laboral -el popularmente conocido problema del "multirut"-, no parece existir claridad en la dogmática sobre una distinción conceptual fundamental en la materia: la idea de empleador aparente y la de grupo de empresas. En este artículo, a partir de esa distinción, se analiza la problemática señalada y se proponen alternativas de solución por la vía de una reforma legal, en especial en cuestiones referidas a derechos del trabajo de carácter colectivo.

Palabras clave: grupo de empresas, empleador aparente, derechos laborales colectivos, levantamiento del velo.

\section{SUMMARY}

Almost a decade after the start of the discussion on the concept of work -material company popularly known as the problem of "multirut"- there

*Abogado. Doctor en Derecho por la Universidad de Salamanca. Profesor de Derecho del Trabajo en las universidades Diego Portales y Alberto Hurtado. Correo electrónico jose. ugarte@udp.cl. Dirección postal avenida República No 112, Santiago. Artículo recibido el 20 de marzo de 2013 y aceptado para su publicación el 17 de abril de 2013. 
seems to be clearly in the Dogmatic Constitution on fundamental conceptual distinction in the field: the idea apparent employer and the group of companies. In this article, based on this distinction, we analyze the problems noted and alternatives proposed solution through legal reform, especially in matters relating to labor rights collective character.

Keywords: group of companies, employer apparent collective labor rights, lifting the veil.

\section{RÉSUMÉ}

Pratiquement dix ans après les premières discussions sur le concept d'entreprise en matière de travail, connu de façon plus familière comme le problème du "multirut" , la situation reste peu claire sur le plan dogmatique quant à la distinction conceptuelle fondamentale entre l'idée d'employeur apparent et celle du groupe d'entreprises. Sur la base de cette distinction, cet article se penche sur la problématique en question et propose plusieurs solutions possibles par le biais d'une réforme juridique, notamment en ce qui concerne les droits du travail à caractère collectif.

Mots-clés: groupe d'entreprises, employeur apparent, droits collectifs du travail, levée du voile dissimulant l'entité (“disregard of legal entity").

\section{INTRODUCCIÓN:}

LA EMPRESA RED Y LA LEGISLACIÓN LABORAL

El tránsito en las últimas décadas desde la empresa centralizada y vertical, del período denominado fordista, a la empresa en red y horizontal, del innominado período de especialización flexible o posfordista, ha generado un complejo panorama para la organización jurídica de la vida económica dentro de las sociedades capitalistas ${ }^{2}$.

La antigua gran empresa, unidad centralizada de ordenación de los factores productivos, ha dado paso a nueva modalidad de organización que se constituye por múltiples unidades económicas; dichas unidades, que se encuentran ligadas por la propiedad o control financiero, pueden establecer tanto relaciones de coordinación horizontal como de control vertical.

${ }^{1}$ NDT: structuration de grandes entreprises sous de multiples raisons sociales.

${ }^{2}$ Véase Artiles (1995). 
Esta empresa en red, considerada la actual forma empresarial dominante, supone diversos aspectos de organización legal en distintos planos o dimensiones jurídicas:

\section{La dimensión jurídica comercial}

Puede decidir operar bajo la estructura de unidad o pluralidad, según se trate de una o varias personas jurídicas, cuestión permitida por el ordenamiento civil y amparada por el denominado principio de libre constitución de este tipo de organizaciones.

\section{La dimensión jurídica económica}

Puede decidir operar bajo el control directivo de una de ellas por sobre el resto (grupo de empresa), o bajo una forma de coordinación igualitaria (empresa red horizontal), decisión amparada por la libertad económica y el derecho de propiedad reconocidas constitucionalmente ${ }^{3}$.

\section{La dimensión jurídica laboral}

Puede constituir una sola estructura de mando y subordinación (un empleador) o distintas estructuras de subordinación (pluralidad de empleadores), cuestión permitida al amparo de la libertad de trabajo constitucional (artículo 19, número 16 de la Constitución).

En principio, la forma o estructura que adoptará la empresa red en cada una de estas dimensiones es independiente entre sí, y se encuentra amparada dentro de la libertad de personalidad jurídica, económica y la de trabajo, respectivamente.

Ahora, la existencia de estos principios legales no impide que su ejercicio pueda, en determinados supuestos, generar problemas y situaciones de conflicto, al entrar en pugna con la regulación de la legislación laboral. Dentro de aquéllos resultan de especial relevancia el problema de los denominados "grupos de empresas" y el del uso fraudulento de la personalidad jurídica o del "empleador aparente":

a. La empresa puede adoptar una forma plural en lo referido a su organización jurídico-comercial (múltiples razones sociales), pero existir, al mismo tiempo, control económico o dirección unitaria de una de esas unidades por sobre las restantes, generándose el problema denominado de los "grupo de empresas".

${ }^{3}$ Ugarte Vial (2012) pp. 701-702.

${ }^{4}$ Para la revisión de la problemática de los grupos de empresas véase BAZ (2002). En Chile, véase Rojas y Aylwin (2005). 
b. La empresa red puede adoptar una forma plural en lo jurídico (pluralidad de razones sociales), pero tener una sola estructura laboral de mando y subordinación respecto de los trabajadores (único empleador), situación constitutiva del problema del "empleador aparente".

Esta distinción es relevante en cuanto ambas problemáticas se han visto confundidas con frecuencia el debate político nacional sobre el concepto de empresa. En rigor, sólo la segunda -el uso fraudulento de la personalidad jurídica o empleador aparente-, corresponde a lo que públicamente se ha dado en conocer como el problema de las "cientos de razones sociales".

Como es posible advertir, existe una clara diferencia entre la problemática del grupo de empresas -pluralidad jurídica con unidad de control económico-, con la del uso fraudulento de la personalidad jurídica -pluralidad jurídica con una estructura única de subordinación laboral-.

En efecto, de la literatura comparada sobre el grupo de empresas, que maneja un verdadero festín de conceptos, se seguiría que lo que liga a las diversas personas jurídicas es el control económico de una de ellas por sobre las restantes, ya sea que se verifique por un control financiero o societal $^{5}$ o ya sea que se verifique por una dirección económica unitaria, cuestiones manifestadas por un conjunto diverso de indicios económicos (propiedad común, plantilla única, comunicación efectiva de patrimonios, control de políticas de venta o de personal, etc). Mientras que en el caso del empleador aparente lo que vincula a las personas jurídicas es la existencia de un vínculo de subordinación laboral, manifestado a través de los indicios laborales tradicionales, entre una de esas empresas y los trabajadores formalmente contratados por todas ellas.

En el grupo de empresas, no existe problema de evasión de la condición de empleador, porque cada una de ellas es una estructura de mando y subordinación genuina; el problema es, en rigor, el del control o dirección económica de una de las sociedades respecto de las restantes personas jurídicas, y cómo encontrar un centro de imputación jurídica que opere en sustitución total o parcial del empleador. Es decir, el problema central es cómo superar la figura jurídica de empleador, para encontrar una unidad jurídica superior -la empresa de grupo-, a la que convertir en un nuevo centro de imputación laboral ${ }^{6}$.

${ }^{5}$ Terradillos (2000a) p. 64.

${ }^{6}$ Precisamente la complejidad para construir esa noción legal de grupo de empresa, se deriva la escasa regulación legal de dicho fenómeno, salvo Brasil y Argentina, no existe legislaciones laborales que se refieran a esta figura. En el caso brasileño, la CLT señala en su artículo 2, número 2, que existe un grupo de empresas cuando "una o más empresas, teniendo incluso, cada una de ellas, personalidad jurídica propia, se encuentran bajo la dirección, 
En el caso del empleador aparente (uso fraudulento de la personalidad jurídica), por el contrario, el problema es bastante más simple y tradicional: superar las formas jurídicas para identificar al verdadero empleador como centro tradicional de imputación jurídica laboral.

Para enfrentar este último problema, hace entrada al escenario la idea de modificar el concepto de empresa del artículo 3 del Código del Trabajo. En efecto, un paso para la solución sería la reforma de los términos en que se le define en dicho artículo, de modo que, manteniendo sus notas actuales de una organización de medios ordenadas bajo una dirección común y para el logro de ciertos fines, reemplazará el equívoco término "una individualidad legal determinada", por la mención directa del empleador, bajo una fórmula que podría ser, utilizando las palabras del antiguo Código del Trabajo de 1931, de "explotada por un empleador" o “cuya explotación esté a cargo de un empleador" o, derechamente, su eliminación, propuesta por la reforma laboral del 1999 y que se ha reestrenado en el debate actual en la Cámara de Diputados.

En lo que sigue nos referiremos al problema del uso fraudulento de la personalidad jurídica para efectos laborales y no a la problemática del grupo de empresas. En ese sentido, revisaremos la problemática respectiva en dos pasos:

- primero, la explicación del problema desde el punto de vista jurídico-laboral, particularmente en su dimensión de las relaciones colectivas de trabajo (II y III) y

- $\quad$ segundo, la revisión de posibles alternativas de modificaciones legislativas que permitirían resolverlo (IV).

\section{El PROBLEMA JURÍdico DETRÁS DEL CONCEPTO DE EMPRESA CONTEMPLAdO EN EL ARTÍCUlO 3 DEL Código DEL TRABAJO:}

EL EMPLEADOR APARENTE

El núcleo del problema englobado bajo la expresión "del concepto de empresa" tiene relación con la inadecuada solución judicial al problema de la tensión entre la pluralidad jurídica en una empresa red, con la noción unitaria de empleador en el ejercicio de los derechos laborales, pero particularmente en el ámbito de los derechos colectivos del trabajo. De hecho, como explicaremos en adelante, el problema se suscita, precisamente, por la falta de coherencia de la jurisprudencia judicial, en especial, de la Corte Suprema, en la aplicación del principio de primacía de la realidad.

control o administración de otra". De hecho, es casi ya un ritual de la doctrina laboral comparada quejarse de la inexistencia de regulación legal. Véase Pérez de los Cobos (1998). 
El problema puede ser expuesto en las siguientes tres puntos:

A. Tensión entre el principio de la personalidad jurídica y la noción legal de empleador, para los efectos de la imputación normativa de derechos laborales tanto individuales como colectivos.

B. Resolución judicial de la tensión señalada (personalidad jurídica vs. empleador) en el ámbito de los derechos individuales a favor de la noción de empleador, por la vía del principio de primacía de la realidad y la noción de unidad económica.

C. Resolución judicial de la tensión señalada en el ámbito de los derechos colectivos a favor del principio de la personalidad jurídica, por la vía de la utilización del concepto de empresa contemplado en el Código del Trabajo.

A. Tensión entre el principio de la personalidad jurídica y la noción legal de empleador, para los efectos de la imputación normativa de derechos laborales tanto individuales como colectivos

La idea de persona jurídica entendida como la atribución por el sistema jurídico a un ente ficticio -en los términos de nuestro Código Civil- de la aptitud para ser titular de derechos y obligaciones, con prescindencia 190 de las personas naturales que la originen o la compongan, es una pieza clave en la concepción formalista que guía la normativa que regula desde el Derecho Privado las actividades empresariales en el contexto de una economía capitalista?.

Y especialmente, la constitución de sociedades mercantiles -forma por excelencia de las personas jurídicas en el ámbito económico- como acto formal que permite mantener incomunicados los patrimonios de la persona jurídica con la de los dueños o socios de la misma, y que se muestra como el modo paradigmático de organización de la actividad económica.

Desde el siglo XIX se construyó en torno a esta ficción jurídica, de gran éxito para aprovechar los beneficios económicos de las nacientes económicas industriales, el dogma del hermetismo jurídico, esto es, la total insensibilidad entre la persona jurídica y sus titulares o miembros, mediando una relación de total extrañeza entre ellos para efectos legales ${ }^{8}$.

Ese hermetismo se tradujo en una construcción exageradamente formalista, que sólo exigió para la existencia de una persona jurídica la

${ }^{7}$ A diferencia del Code Civil francés, el Código Civil chileno regula y define a la persona jurídica en su artículo 545 y ss. De este modo, se señala: "Se llama persona jurídica una persona ficticia, capaz de ejercer derechos y contraer obligaciones civiles, y de ser representada judicial y extrajudicialmente".

${ }^{8}$ López Díaz (2003) p. 17. 
manifestación de la voluntad de los particulares, concentrando el control público en el acto fundacional o constitutivo. Y por causa de ese formalismo se forjó la posibilidad de que la persona jurídica se utilizara para fines jurídicamente reprochables, como defraudar a terceros o eludir el cumplimiento de las leyes.

Por ello, desde hace ya varias décadas se viene imponiendo la idea de que:

"reducido el concepto de persona jurídica a una mera figura formal, un recurso técnico, se presta su utilización para unos objetivos que no son los propios de la realidad social para la que nació dicha figura, sino otros muy distintos privativos de los individuos que lo integran. Los socios podrán valerse de la sociedad para eludir el cumplimiento de las leyes, para desligarse de las obligaciones contraídas con terceros y, en general, para defraudar los intereses de éstos" $"$.

Cabe apuntar que el dogma del hermetismo de la persona jurídica carece de consagración constitucional, por lo que fácilmente puede ceder o ser superado si se pone en conflicto con diversos bienes o instituciones jurídicas en situaciones concretas; de este modo, se dará satisfacción a estos intereses, a través de la regulación específica que otorgan otras disciplinas ante dichas situaciones. Desde antiguo la doctrina comparada sostiene:

"si la cuestión a resolver es propia de la disciplina abreviada que supone la persona jurídica, se aplica la normativa de la persona jurídica, pero si la cuestión corresponde a la esfera de acción de otra disciplina distinta, entonces la normativa aplicable será la que corresponde a cada caso dado: aquella que el derecho ha establecido teniendo en vista la situación específica de que se trate. La prescindencia de un concepto hipostático de la persona jurídica se impone cuando tras ella pretendida esconderse una conducta ilegal" 10 .

La utilización abusiva de la personalidad jurídica puede corresponder a distintas situaciones, pero de especial relevancia es el fraude a la ley, esto es, emplearla como un modo de obtener un resultado legalmente prohibido. En esos casos:

${ }^{9}$ BOLdó (2000) p. 43.

${ }^{10}$ Dobson (1985) p. 87. 


\begin{abstract}
"una ley puede quedar burlada con la utilización de la figura de la persona jurídica cuando los individuos a quienes la norma se dirige se ocultan tras de aquélla, tanto si ya existía como si sólo fue creada para tal fin, con lo que logran sustraerse al mandato legal. El mandato o la prohibición de la norma no aparece de esta forma formalmente infringido por el sujeto afectado porque sólo realiza los actos que le están prohibidos por medio de la persona jurídica"11.
\end{abstract}

En caso del fraude a la ley laboral se elude una regla o un principio imperativo en este ámbito, por la vía de utilizar una norma de cobertura de carácter civil o mercantil. Y ésa es, en rigor, la situación que se produce, en determinados casos, entre la persona jurídica y la noción de empleador propia del Derecho del Trabajo. Específicamente cuando, utilizando la libre constitución de las personas jurídicas al amparo de las normas civiles y mercantiles, se logra el resultado de evitar la condición de empleador, atribuyéndosela a una persona jurídica distinta, evadiendo el cumplimiento de los derechos laborales de los respectivos trabajadores.

En efecto, la noción legal de empleador, centro de imputación de los derechos laborales, tanto individuales como colectivos, no es necesariamente coincidente con la noción de persona jurídica, en cuanto la primera 192 exige que la segunda ejerza el mando y subordinación de los trabajadores respectivos.

En ese sentido, la noción de empleador establecida en el artículo 3 del Código del Trabajo, supone un elemento real que supera a la persona jurídica: el ejercicio efectivo de la potestad de mando propia de la idea de subordinación jurídica. No hay, por tanto, para la legislación laboral, empleador si la persona jurídica de que se trata no ejerce dicho mando y subordinación.

Atendido lo anterior, es posible y jurídicamente lícito, que una empresa decida, desde la perspectiva jurídico-mercantil, organizarse en torno a un conjunto de personas jurídicas distintas $\mathrm{y}$, al mismo tiempo, constituya, desde el punto de vista jurídico-laboral, una pluralidad de empleadores. El problema, sin embargo, se presenta cuando esa pluralidad jurídicomercantil corresponde a una única unidad de mando y subordinación constituido por un sólo empleador.

En este último caso, la multiplicidad de personas jurídicas que suscriben formalmente los contratos de trabajo, permiten lograr un resultado prohibido por la ley laboral: que se utilice como centro de imputación normativa, y lugar de ejercicio de derechos laborales, a quien no tiene la calidad de empleador para efectos de las normas laborales. Es en este

${ }^{11}$ Boldó (2000) p. 74. 
caso que se puede hablar de uso fraudulento de la personalidad jurídica en el ámbito laboral.

$\mathrm{Y}$ en ese caso, el uso fraudulento en el ámbito laboral puede afectar tanto derechos individuales -por ejemplo, si la persona jurídica que firma los contratos es la menos solvente para responder de las utilidades o si se hace rotar a los trabajadores entre las distintas personas jurídicas para afectar el monto de su indemnización en caso de despido- o derechos colectivos -como si la empresa se dividiera artificialmente haciendo imposible el ejercicio efectivo del derecho a la negociación colectiva-.

La forma en que el Derecho Comparado ha respondido al uso fraudulento de la personalidad jurídica corresponde a la creación de diversos mecanismos de penetración del velo corporativo o societario, permitiendo sortear la persona jurídica para llegar al sustrato personal de sus titulares o miembros.

Se da lugar, así, a lo que la jurisprudencia estadounidense denominó en su momento la doctrina del disregard of legal entity ${ }^{12}$, o en su traducción del Derecho continental como la doctrina del "levantamiento del velo", que consiste en un

"remedio jurídico mediante el cual resulta posible prescindir de la forma de sociedad o asociación con que se haya revestido un grupo de personas o bienes, negando su existencia autónoma como sujeto de derecho frente a una situación jurídica particular" ${ }^{13}$.

Y en el caso de la legislación laboral, en el Derecho Comparado es usual penetrar el velo de las personas jurídicas que simulan contratar trabajadores, pero que ocultan el verdadero empleador, mediante el fundamento -a esta altura universal- del principio de supremacía de la realidad ${ }^{14}$. Principio de primacía de máxima importancia para que la legislación laboral puede fundamentar jurídicamente dicho levantamiento ${ }^{15}$. Por eso, se ha señalado:

${ }^{12}$ Fundada en la "equidad" la jurisprudencia judicial de Estados Unidos dio lugar desde la década de 1930 a la penetración de la persona jurídica (piercing the veil), descorriendo el velo corporativo en diversas circunstancias. Especialmente importante será la doctrina del alter ego: debe levantarse el velo cuando entre dos personas jurídicas existe tal dominio y control de una sobre la otra, que esta última no es sino un alter ego de la dominante utilizada para obtener resultados antijurídicos.

${ }^{13}$ Dobson (2000) p 11. Para un pormenorizado estudio en Chile, véase López (2003).

${ }^{14}$ En el Derecho Privado, Civil o Mercantil, a falta de la potente herramienta del principio de primacía realidad, se han tenido que utilizar diversos fundamentos para el levantamiento del velo: al abuso del derecho, el fraude a la ley, la doctrina de los actos propios o la buena fe. Ugarte Vial (2012) pp. 699-723; López (2011) pp. 9-52.

${ }^{15}$ En algunos casos con reconocimiento constitucional, como ocurre en Colombia (art. 53), y con profuso reconocimiento a nivel legal: artículo 14 de la Ley de Contrato de 


\begin{abstract}
"cuando el sujeto interpuesto o testaferro, unipersonal o no, carece de visos de organización, la teoría de la primacía de la realidad lleva a desestimar a esa persona aparente, a ese sujeto que se interpone vistiendo los ropajes que lo hacen parecer, sin serlo, una verdadera empresa, para dejar al descubierto la autentica relación que se tiene entre el trabajador y la empresa que lo inserta en su organización, y aprovecha su trabajo" 16 .
\end{abstract}

Aunque no suele usarse entre laboralistas la denominación levantamiento del velo, ésa es la técnica usada en los diversos ordenamientos laborales para reprimir el uso fraudulento de la personalidad jurídica, incluido, como veremos a continuación, el chileno ${ }^{17}$.

Precisamente, a revisar cómo ha enfrentado nuestro Derecho Laboral el levantamiento del velo corporativo en los casos de abuso de personalidad jurídica en la forma de empleador aparente, y cómo en ello ha incidido el concepto de empresa, dedicaremos los puntos que siguen.

B. Resolución judicial de la tensión señalada (personalidad jurídica vs. empleador) en el ámbito de los derechos individuales a favor de la noción de empleador, por la vía del principio de primacía de la realidad y la noción de unidad económica

En nuestro país, cuando se ha planteado judicialmente el problema del empleador aparente, entendido como uso de una pluralidad jurídica (multiplicidad de razones sociales) que corresponde a un sólo empleador y que afecta el ejercicio de derechos laborales individuales, la jurisprudencia ha actuado levantando el velo corporativo, sosteniendo sus fallos en dos ideas combinadas: la unidad económica y la aplicación del principio de primacía de la realidad.

Trabajo en Argentina, artículo 9 de CLT en Brasil, artículo 17 del Código del Trabajo de El Salvador, etc. En el resto de los países, como el caso chileno, de amplia recepción judicial.

${ }^{16}$ Hierrenzuelo y NúÑEz (20039 p. 101.

${ }^{17}$ Así, por ejemplo, en el caso español se ha sostenido que la "jurisprudencia trata de poner de relieve la antinomia entre la realidad formal y la realidad material o el fraude a la ley, criterio que igualmente ha sido puesto de relieve y que avala la declaración de unidad empresarial. Nos percataremos de que la praxis empresarial ensaya la elusión de reglas del Derecho, no infringiéndolas frontalmente, bien que buscando un medio artificioso que consiga hacerlas vanas y sustraerse a ellas". En esos casos, "el levantamiento del velo permite la confirmación de una realidad distinta conformada por la diversificación de sociedades, tal y como ocurre en supuestos de sociedades pantallas que no tienen otro cometido que el de eludir responsabilidades, entre otras las laborales".TERRADILLOS (2000 b) p. 78 y ss. 
A partir de la apreciación de una serie de indicios -patrimonio y dirección común, unidad de administración, identidad de representantes, unidad de gerencia y mando- la jurisprudencia judicial chilena ha construido un régimen de responsabilidad laboral solidaria, que tiene como fundamento la unidad económica que constituyen las diversas personas jurídicas afectas a dichos indicios, y que utiliza disimuladamente y sin aspavientos la técnica del levantamiento del velo ${ }^{18}$.

En ese sentido, cuando se ha tratado del ejercicio de derechos laborales individuales, en particular, de indemnización, nuestra jurisprudencia ha actuado con solvencia dogmática, aplicando el principio de primacía de la realidad y levantando los velos corporativos o razones sociales involucradas en el uso abusivo de la personalidad jurídica ${ }^{19}$.

Y precisamente por lo anterior, es que el debate público y político sobre la reforma del concepto de empresa, no alcanza a esta dimensión individual de los derechos laborales, ya que la jurisprudencia judicial, incluyendo la Corte Suprema, no ha permitido en esta parte del problema que las formas sociales impongan fraudulentamente un empleador aparente.

Dicho de otro modo, en el ámbito de las relaciones laborales individuales, la reforma del concepto de empresa, entendido como el problema del uso fraudulento de la persona jurídica, casi podría calificarse de innecesaria: la jurisprudencia judicial ha levantado el velo de las razones sociales, deteniendo el fraude laboral del uso de múltiples razones sociales que encubren un sólo empleador.

\section{Resolución judicial de la tensión señalada en el ámbito de los derechos colectivos a favor del principio de la personalidad jurídica, por la vía de la utilización del concepto de empresa contemplado en el Código del Trabajo}

Debería preverse la situación del empleador aparente, cuando se trata del ejercicio de los derechos colectivos, especialmente el derecho a la sindicación y la negociación colectiva, fuera resuelta del mismo modo que la de los derechos individuales, esto es, que la jurisprudencia judicial procediera a levantar el velo corporativo en aplicación del principio de primacía de la realidad.

Sin embargo, ello no ha sido así. La Corte Suprema ha resuelto el problema de la tensión entre la multiplicidad de personas jurídicas (razones

${ }^{18}$ Para revisar jurisprudencia de levantamiento del velo por empleador aparente en casos concretos de relaciones laborales individuales, véase RoJAS y AYLWIN (2005) p. 93-100.

${ }^{19}$ Esta aseveración se ve confirmada por la propia dogmática comercial chilena, que, sobre la base de estudios jurisprudenciales, detecta esta regularidad en los fallos de los tribunales laborales. Para un análisis empírico en este sentido, véase VARELA (2011) pp. 96-105. 
sociales), y la existencia de una sola estructura de mando y subordinación (un empleador), a favor de las primeras, validando la práctica de que la división societal se traduzca en una seria afectación de los derechos colectivos del trabajo.

En ese sentido, esta jurisprudencia ha sostenido:

“Que para comprender el sentido de la 'unidad económica', en los términos descritos en el artículo $3^{\circ}$ del Código laboral, en forma reiterada la Excma. Corte Suprema ha señalado que, en aquellos casos en que las empresas tienen diversidad de rubros, personalidad jurídica distinta y un rut diferenciado, aun cuando funcionen en la misma propiedad o inmueble, no procederá considerarlas como una unidad económica" ${ }^{20}$.

En este punto, cabe preguntarse: ¿̇sobre la base de qué argumento jurídico la Corte Suprema soslaya en materia colectiva el principio de primacía de la realidad y de la unidad económica que ha utilizado frecuentemente en materia de derechos laborales individuales, y en vez de levantar el velo corporativo, decide más bien protegerlo o reforzarlo?

Aquí, precisamente, hace su entrada el concepto legal de empresa del 196 artículo 3 del Código del Trabajo. Y lo hace para que la Corte Suprema resuelva el problema del empleador aparente en sentido inverso a lo hecho en materia derechos individuales: para reforzar el hermetismo de las personas jurídicas en perjuicio de la primacía de la realidad y el levantamiento del velo, alejando los derechos colectivos del verdadero empleador.

Nuestra legislación ha dedicado una disposición expresa para definir que se va a entender por empresa, contenida en el inciso tercero del artículo 3 del Código del Trabajo:

"Para los efectos de la legislación laboral y de seguridad social, se entiende por empresa toda organización de medios personales, materiales e inmateriales, ordenados bajo una dirección, para el logro de fines económicos, sociales, culturales o beneficios, dotada de una individualidad legal determinada".

De este modo, podemos partir señalando que se trata de una noción compuesta, que debería exigir la concurrencia de todos y cada uno de los elementos señalados en una organización económica determinada para ser considerada "empresa", pues todos forman parte de una noción única e integrada de la misma:

${ }^{20}$ Corte Suprema, 16 de noviembre de 1999, LexisNexis 16.373. 
a) Una organización de medios personales, materiales e inmateriales

La amplitud de la fórmula legal es máxima, en el sentido de que todo medio sea de carácter humano como de carácter patrimonial, puede conformar parte de una empresa, siempre que se encuentre inserto en una organización.

b) Bajo una dirección común

Según la ley laboral, no basta un conjunto desordenado o meramente yuxtapuesto de medios personales o patrimoniales, sino que se requiere una organización que los integre, la que está dada extrínsecamente por un control o dirección común, que corresponde a la figura del empleador.

c) Para el logro de fines económicos, sociales, culturales o benéficos

La nota de amplitud que el legislador pretendió atribuir a la noción de empresa, queda de manifiesto con absoluta claridad en no restringir sus finalidades al "lucro", sino ampliarlas a la persecución de cualquier beneficio posible de ser conseguido con la respectiva organización. Precisamente, por no tratarse del concepto económico de empresa, sino de uno jurídico laboral, es que una persona natural que sólo tiene a cargo un sólo trabajador y sin fines de lucro (como el empleador de casa particular), reúne en torno a sí todos los elementos constitutivos que de acuerdo con el legislador componen una empresa laboral.

d) Dotada de una individualidad legal determinada

Se trata, quizá, del elemento más problemático de la definición del Código del Trabajo, en especial, por la inusual expresión elegida por el legislador, que no se encuentra recogida en ningún otro texto legal de nuestro ordenamiento jurídico.

¿Qué se quiso decir con "individualidad legal determinada”?

La doctrina ha señalado:

"por individualidad legal determinada no debe entenderse el atributo de la personería jurídica, basta con un ser jurídico".

Dicho de otro modo, lo que el legislador exigiría es que alguien que tenga la calidad de sujeto de derecho (todo ente a quien el ordenamiento jurídico le reconoce la capacidad para ser titular de derechos y de obligaciones), opere como el soporte de la empresa, y no necesariamente que se trate 
de una persona jurídica constituida de acuerdo con los procedimientos establecidos en la ley.

El problema, sin embargo, es que la imprecisa expresión legal ya anotada, ha permitido la construcción de una concepción fuertemente formalista del concepto, induciendo a poner acento en la idea de que basta con tener la calidad de sujeto de derecho, esto es, una persona jurídica, para poder ser considerado como el soporte de una organización de medios a la que se refiere el artículo 3 de la ley laboral.

Vincular la exigencia de una "individualidad legal determinada" sólo a la idea de personalidad jurídica, esto es, a un ente que tenga la calidad de sujeto del derecho, vacía el concepto de empresa a efectos laborales, ya que le ha permitido a cierta jurisprudencia judicial entender que se podría tener dicha calidad sin tener necesariamente la de empleador. Así, bastaría que una empresa madre se divida en forma artificiosa por la vía de constituir varias personas jurídicas o razones sociales, para que se entienda que estamos frente a varias empresas en términos laborales, aunque paradójicamente la realidad indique lo contrario, esto es, que se trata de una sola organización material bajo un único mando y sólo exista un empleador.

Y SU PAPEL EN LA RESOLUCIÓN DEL PROBLEMA DEL EMPLEADOR APARENTE EN LOS DERECHOS COLECTIVOS DEL TRABAJO

Una de las situaciones más problemáticas para el ejercicio de los derechos laborales en casos de empleador aparente, y que en rigor dio origen a la primera propuesta sobre el tema en la reforma laboral de la ley $\mathrm{N}^{\mathrm{o}} 19.759$ de 2001, y al confuso debate sobre el concepto de empresa, corresponde a lo que podríamos denominar la fragmentación sindical derivada de procesos de filialización y división societal dentro del marco de la descentralización productiva.

En efecto, frente a procesos como la división y la filialización de una empresa en Chile, y ante la interrogante de qué ocurre con el respectivo sindicato con los trabajadores traspasados a la nueva sociedad filial o ligada, la respuesta debería plantear que por existir dos empresas distintas, entonces, la afiliación de dichos trabajadores no podría sobrevivir, como por lo demás lo ha sostenido la Dirección del Trabajo, pues se encuentran en una empresa distinta a la del sindicato.

Así lo explica con meridiana claridad este servicio al señalar:

"cada una de las nuevas sociedades constituye una nueva empresa, dotada de identidad legal propia, motivo por el cual sus trabajado- 
res no pueden formar parte del sindicato constituido en la empresa de origen, quedando automáticamente desafiliados al instante de su traspaso a las nuevas entidades, de acuerdo a lo expresado antes en cuanto a la base de los sindicatos de empresa" ${ }^{21}$.

En consecuencia, el problema central a resolver en esa materia se presenta cuando la realidad indica algo distinto: las empresas ahora divididas o filializadas siguen operando tan estrechamente ligadas, que los trabajadores traspasados continúan, en los hechos, prestando servicios en la misma estructura productiva. En dicho caso, cंdebe entenderse que se extingue la afiliación sindical de dichos trabajadores, ahora incorporados formalmente a una nueva empresa, aun cuando en la práctica siguen sometidos a la misma organización material previa a la división o filialización?

Como es fácil de advertir, aquí la posible interpretación de la noción legal de empresa puede generar un importante problema para la protección del sindicato y para la afiliación sindical de ciertos trabajadores (los traspasados a las nuevas filiales o las ligadas).Y en este caso, precisamente, a propósito de la definición de empresa contenida en el artículo 3 del Código, en particular, en su referencia a una "individualidad legal determinada", se producen varias posiciones interpretativas:

\section{a) Tesis formalista}

Expuesta de forma sintética esta tesis sostiene que si una entidad se divide o filializa, por el hecho de que el resultado de tales operaciones desemboque en entes con personalidad jurídica distinta, da origen a empresas diversas a efectos laborales y, en esas condiciones, los trabajadores han sido traspasados a una nueva, más allá de la realidad material en que se vayan a prestar los servicios, lo que impide mantener su afiliación al sindicato de su antigua empresa.

Dicho de otro modo, la existencia de una pluralidad jurídica es el elemento central y preeminente para considerar que no existe una sola empresa para efectos laborales, con prioridad interpretativa sobre la realidad material de los servicios. Esa idea se desprende de alguna jurisprudencia de la Corte Suprema que señala:

"Que según se ha asentado en la sentencia en estudio, las demandadas de autos, si bien presentan elementos de vinculación muy marcados tanto en lo que dice relación a su propiedad como a quien ejerce el control y su representación, estos no resultan suficientes,

${ }^{21}$ Ordinario 1117-32, 4 de febrero de 1991. 
como para que puedan ser calificadas como una sola empresa, desde que no se ha establecido que desarrollen un mismo giro, que sus actividades se hayan coordinado para el logro de objetivos comunes y, en fin, que constituyan una sola identidad jurídica"22.

Para esta tesis la existencia de diversas razones sociales implica la existencia de diversas empresas, aunque en la realidad no se trate sino de una sola organización productiva. El argumento central corresponde a la expresión "dotada de una individualidad legal determinada" utilizada por el artículo 3 del Código del Trabajo. Si existen varias identidades legales o razones sociales, aunque en la realidad se trate de una unidad de mando y dirección de los trabajadores, estamos, sostiene esta visión, ante varias empresas.

\section{b) Tesis del vínculo de dependencia}

La Dirección del Trabajo, en pronunciamientos disonantes con la tesis anterior, ha intentado resolver el problema de la afiliación sindical en los procesos de fragmentación empresarial, desentendiéndose del concepto de empresa, para utilizar derechamente la idea de empleador.

200 De este modo, la Dirección del Trabajo ha sostenido que frente a los procesos de división o filialización, lo relevante, más que determinar si se trata de entidades distintas al tenor de lo establecido en el artículo 3 del Código del Trabajo, es determinar quién es el empleador, definido en ese mismo precepto legal como aquella persona natural o jurídica que utiliza los servicios subordinados de otro.

De este modo, la tesis ya antigua de este servicio logra, evadiendo el complejo e impreciso concepto legal de empresa, el objetivo de impedir que por medios de simples ejercicios de diseño legal se afecte la afiliación de trabajadores con la empresa real (empleador) en la que se encuentran insertos:

"Atendido a los diversos factores que conforman la realidad de hecho precedente, necesario es concluir que los trabajadores que aparecen contratados por la empresa Inhumar Lida., prestan servicios personales a la empresa Inhamar S.A., la que efectivamente los recibe y utiliza para sus fines sociales, bajo subordinación y dependencia, en el marco diario de jornada de trabajo. La indicada realidad, que determina vínculos de dependencia respecto

${ }^{22}$ Zúñiga y otros con Comercial Magno y Distribuidora Magallanes, rol N 6070-2009, de 11 de noviembre de 2009. 
de la empresa que organiza y administra la respectiva actividad laboral, no resulta alterada por la sola circunstancia de que los mismos trabajadores puedan aparecer formalmente vinculados a otra empresa, y ello porque, en todo caso, dicho acuerdo en cuanto expresión de voluntad, resulta jurídicamente ajeno y, por lo mismo, ineficaz para configurar una situación contractual respecto a la relaciones laborales que efectivamente se producen día a día con la empresa Inhamar S.A.

En consecuencia, de conformidad con lo expuesto y disposiciones legales citadas, cúmpleme en informar a Ud. que los trabajadores formalmente contratados por la Empresa Inhamar Ltda., prestan servicios efectivamente bajo subordinación y dependencia de la Empresa Inhamar S.A., por lo que no existe impedimento jurídico para que se afilien al sindicato constituido en esta última"23.

Sirve, como es fácil de advertir, de apoyo a esta tesis interpretativa el principio de primacía de la realidad, y la noción de subordinación jurídica, que como ya señalamos, es la doctrina de la propia Corte Suprema en materia de derechos individuales.

\section{c) Tesis de la empresa como ente compuesto}

En esta tesis, que la doctrina laboral entiende como la correcta, la respuesta pasar por sostener que la empresa es un conjunto de elementos constituidos por la existencia de una organización de medios personales y patrimoniales bajo una dirección común, más el soporte legal construido por el empleador, de modo tal, que más allá de situaciones de pluralidad jurídica ("varias razones sociales"), la existencia de una unidad material (una organización de medios bajo una dirección común), determinaría la existencia para efectos laborales de una sola empresa.

De esta forma, aquellos procesos de filialización o división que terminan en una pluralidad de empresas, que en el plano jurídico no laboral sean distintas, pueden ser consideradas como una sola una desde el punto de vista laboral, si constituyen una sola organización de medios bajo una dirección común, como lo preceptúa el ya tan citado artículo 3 del Código del Trabajo, permaneciendo en esos casos perfectamente vigente la afiliación al sindicato de la empresa de origen de aquellos trabajadores traspasados a las filiales, o permitiendo a futuro la afiliación a dicho sindicato de los incorporados a esta últimas.

${ }^{23}$ Ordinario 6604/395, 1 de diciembre de 1993. 
La jurisprudencia judicial que acoge esta idea ha señalado

"que si bien, formalmente cada una de las demandadas son empresas distintas, aunque con importantes vínculos societarios, lo cierto es que en la realidad, en la práctica, actúan de forma concertada como una sola unidad o empresa, valiéndose de los medios materiales e inmateriales, con miras a obtener un objetivo común, el que se consigue con el trabajo coordinado de cada una de estas empresas, las que realizan labores complementarias, cumpliendo así un ciclo único que tiene por objeto maximizar el rendimiento y las utilidades de la empresa, conformando así una sola empresa o unidad económica, en los términos del artículo 3 del Código del Trabajo" 24 .

De estas distintas formas de lectura del artículo 3 del Código del Trabajo, ha tendido a tener cierta preeminencia la tesis formalista que confunde empresa con persona jurídica y genera todos los problemas derivados del empleador aparente en el ámbito laboral colectivo.

En ese sentido, el riesgo para la protección del sindicato es evidente: cada vez que una empresa decida emprender alguno de los procesos 202 de filialización ya señalados no quedará, entonces, más que irremediablemente entender que el resultado es la existencia de varias empresas distintas desde el punto de vista laboral y, por ende, los trabajadores de cada una deberán construir en ellas su respectiva afiliación sindical, con prescindencia del hecho de que la realidad productiva indique que se trata de una y no de varias empresas.

En pocas palabras, el dominio de la lectura formalista del concepto del artículo 3 del Código del Trabajo, que confunde empresa con la idea de ser titular de una personalidad jurídica, necesaria e indefectiblemente determina que la fragmentación empresarial desembocará en la fragmentación sindical, aunque dicha división sólo se verifique en el papel -y no en la realidad-.

En fin, como ha quedado explicado, el núcleo del problema de la definición de empresa del artículo 3 y su referencia a "una individualidad legal determinada", es que ha permitido sostener frente al problema del "empleador aparente" una tesis que aquí llamaremos formalista, que ha resuelto el problema de la tensión entre la multiplicidad de personerías jurídicas (razones sociales) y la existencia de una sola estructura de mando y subordinación (un empleador), a favor de las primeras, validando la práctica de que la división societal se traduzca en una seria afectación

${ }^{24}$ Segundo Juzgado de Letras del Trabajo de Santiago, RIT 0-2017-2012. 
de los derechos colectivos del trabajo, especialmente la sindicalización y la negociación colectiva.

En la afiliación sindical en los procesos de división y filialización, la actual definición de empresa provoca, por su referencia a "una individualidad legal determinada", problemas interpretativos, que tienen como resultado la falta de una adecuada protección a los derechos colectivos o sindicales, en especial, el mantenimiento de la afiliación sindical y, en consecuencia, la negociación colectiva con el verdadero empleador.

En este último caso, la multiplicidad de personas jurídicas que suscriben formalmente los contratos de trabajo, permiten a la empresa lograr un resultado que contraviene la ley laboral: que se utilice como centro de imputación normativa, y lugar de ejercicio de derechos de sindicación y negociación colectiva, a quien no tiene la calidad de empleador para efectos de las normas laborales, impidiendo, de paso, negociar colectivamente con el empleador efectivo.

\section{Alternativas de SOluCión VÍA Reforma legal AL PROBlema DEL USO FRAUDULENTO DE LA PERSONALIDAD JURÍDICA}

EN EL ÁMBITO LABORAL

En rigor, como ya explicamos, el centro del debate legal aquí analizado corresponde al inadecuado trato que alguna jurisprudencia -la que denominamos formalista- viene dando al problema del uso fraudulento de la personalidad jurídica en materia de derechos laborales colectivos, y que hemos denominado el problema del empleador aparente. Todo fundado en una peculiar interpretación del concepto de empresa previsto en el artículo 3 del Código del Trabajo.

En ese sentido, "la razón social como empresa" corresponde a una doctrina judicial. Y por eso, quizá cabe plantearse, al menos en términos especulativos, si antes de ir a la intervención o a la modificación legal, es posible un cambio jurisprudencial desde la propia Corte Suprema que, como lo han hecho ya en esta materia algunas de las Cortes de Apelaciones y Juzgados del Trabajo, acoja la idea de empleador como unidad de sindicalización y negociación colectiva, aplicando las diversas técnicas argumentativas que permitirían sostener ese resultado: el principio de primacía de la realidad, la unidad económica y la subordinación laboral.

Dicho de otro modo, ¿ es posible pensar que la jurisprudencia formalista -incluida la de la Corte Suprema- sea coherente y decida aplicar la misma fundamentación para solucionar los problemas del uso fraudulento de la persona jurídica, a saber, primacía de la realidad y levantamiento de velo, tanto para el ámbito de relaciones laborales individuales como colectivas? 
Esto es altamente improbable. Lo anterior, atendido la fuerte carga ideológica que esa jurisprudencia formalista -incluida la Corte Suprema- exhibe en materias de negociación colectiva, tal como lo acredita la diferencia de trato ya explicada que en esta materia le ha dado dicho tribunal al problema del empleador aparente, dependiendo de la naturaleza colectiva o individual de la relación laboral.

En rigor, la única opción en el corto plazo es, entonces, una reforma normativa en el plano legal. Esta reforma debe ser evaluada, como ha apuntado la teoría de la legislación, desde los diversos tipos de racionalidad jurídica exigibles en la producción de normas jurídicas. Una reforma legal:

- debe tener objetivos claros y precisos (racionalidad jurídico-política),

- debe redactarse de modo que se reduzcan los problemas de vaguedad (racionalidad jurídico-formal) y

- debe lograrse efectivamente el resultado buscado por la ratio legis u objetivo del legislador (racionalidad jurídico-pragmática) ${ }^{25}$.

Las diversas propuestas de reforma legal que se construyan para la solución del problema del empleador aparente deberían ser aquéllas que presenten mejor combinación de las racionalidades señaladas. Revisemos, en ese sentido, estas dimensiones de la racionalidad:

$204 \quad-\quad$ En primer lugar, desde el punto de vista de la racionalidad jurídico política, la propuesta de reforma a la legislación laboral debe tener un objetivo legislativo (ratio legis) preciso y determinado: la solución al problema del empleador aparente en materia de derechos laborales colectivos. En ese sentido, existen, a partir de las finalidades de la reforma legal, dos restricciones claves:

- en primer lugar, no se busca solucionar el problema del grupo de empresas, sino el del uso fraudulento de la personalidad jurídica en materia laboral, como ya se explicó en la primera parte de este artículo.

- En segundo lugar, dicho problema tiene alta relevancia político legislativa en el ámbito de los derechos colectivos del trabajo (sindicación y negociación colectiva), no así en el ámbito de los derechos individuales, en particular, de las indemnizaciones, ya que esta última cuestión ha sido razonablemente resuelta por la jurisprudencia judicial sobre la base de la primacía de la realidad, como ya se explicó.

Por lo anterior, debe ser considerada con poca o escasa racionalidad jurídico-política en esta específica materia, aquellas propuestas de reforma legal que para solucionar el problema

${ }^{25}$ Véase Calsamiglia (1999). 
del empleador aparente en las relaciones colectivas (uso fraudulento de la personalidad jurídica), pretenden dar cabida a la compleja regulación del denominado grupo de empresas ${ }^{26}$. Se trata de problemas distintos, como ya explicamos, que deben tener una solución político-legislativa distinta.

- En segundo lugar, desde la perspectiva de la racionalidad jurídicoformal, es necesario que la reforma legal para solucionar el problema del empleador aparente en materia colectiva, exhiba una alta rigurosidad lingüística para lograr el objetivo deseado legislativamente (ratio legis). La racionalidad formal en la comunicación entre legislador y juez es clave para evitar un típico defecto de la regulación legal laboral en nuestro país como es la vaguedad, esto es, la indeterminación semántica de las normas jurídicas contenidas en una ley, provocan un espacio de discreción judicial que puede terminar frustrando el objetivo o ratio legis perseguido por el legislador.

La reforma del concepto de empresa no puede derivar en una sustitución normativa más compleja e indeterminada que la anterior, que genere mayores espacios para la discrecionalidad judicial, porque eso comporta un alto riesgo que frustre el objetivo legislativo buscado. Tal como ha advertido la literatura

"estas definiciones, a costa de eliminar el definiendum, se utilizan otros términos que, en ocasiones, son de comprensión más ardua que aquél"27.

Por ello, debe considerarse como regla de racionalidad formal-lingüística de esta política legislativa que la eficacia dependerá de la intensidad de la intervención normativa que en definitiva se adopte, debiendo buscarse aquélla que logre mejor combinación entre menor intensidad de intervención normativa, con menor espacio de discreción argumentativa para los tribunales de justicia.

La peor opción, en términos de racionalidad jurídico-formal es proponer una reforma de alta intensidad normativa -como algunas de las

${ }^{26}$ El problema jurídico que plantea el "grupo de empresas" es de mucha mayor complejidad que el del empleador aparente. De hecho, el debate sobre el grupo en materia laboral es especialmente confuso e, incluye, el problema de la regulación de los grupos empresariales fisiológicos y los patológicos, estos últimos equivalen a lo que aquí hemos denominado “empleador aparente”. Véase Pérez de los Cobos (1998). Quizá por esa misma complejidad, es que, salvo Brasil (Ley Consolidada de Trabajo) y Argentina (Ley de Contrato de Trabajo $N^{\circ} 20.744$ de 1974), no existen regulaciones legales en el Derecho Comparado del grupo de empresas.

${ }^{27}$ ItURRALde (1989) p. 39 y ss. 
propuestas parlamentarias existentes- que no garanticen una mínima reducción del espacio argumentativo en esta materia respecto de las decisiones judiciales.

En ese sentido, presentan baja racionalidad formal-jurídica, por presentar alta indeterminación semántica:

a) Las propuestas que buscan reemplazar el actual concepto de empresa del artículo 3 del Código del Trabajo, por nuevas definiciones que presentan componentes de alta indeterminación semántica o de significado

"Para todos los efectos de legislación laboral se entenderá por empresa aquel capital o conjunto de capital perteneciente a una persona natural o jurídica, o bien, a un grupo de personas naturales o jurídicas que se dediquen a una misma actividad comercial o a actividades comerciales relacionadas entre sí, esté o no el capital subdividido en una o más sociedades de cualquier clase, y debiendo estar destinado a producir algún tipo de utilidad a través de la prestación de servicios personales de personas ajenas a la propiedad de dicho capital".

206 En general, estas propuestas, además de poca racionalidad jurídicopolítica, en cuanto buscan regular más bien el problema del grupo de empresas, y no el del empleador aparente, tiene poca racionalidad jurídico formal, en cuanto utilizan conceptos tales como "unidad económica", "capital", "control económico", etc. Dichos conceptos jurídicos indeterminados, combinados con culturas argumentativas altamente contingentes como la nuestra, no garantizan en absoluto el logro del objetivo de política legislativa buscado, pues lejos de reducir el ámbito de discreción judicial lo expanden.

b) Eliminar o modificar el elemento normativo (individualidad legal determinada), en el que se funda la jurisprudencia formalista de "razón social= empresa laboral"

Ha sido la propuesta del gobierno desde 1999, cuando se presentó dentro de la iniciativa de la reforma laboral que culminó en la ley $\mathrm{N}^{\circ} 19.759$, pero fue rechazada en el Congreso Nacional, obteniéndose a cambio, en la negociación parlamentaria, la reforma del artículo 478 del Código del Trabajo que incorporó la figura del subterfugio, la cual, cabe precisar, tal como se adelantó en su momento, no tuvo ninguna utilidad ${ }^{28}$.

${ }^{28}$ UGarte Cataldo (2001). Y esa propuesta se ha repetido en el proyecto de ley de subcontratación por iniciativa parlamentaria. En este caso, la propuesta tenía muy poca 
Cabe señalar que, aunque esta propuesta tienen mayor racionalidad jurídico-formal, en cuanto no agrega un nuevo y potencialmente problemático término o concepto (definiens) en sustitución del definido (definiendum), sino que, más bien, todo lo contrario, se lo resta o elimina, persiste en ella un problema de vaguedad relevante, en cuanto no logra cerrar de modo significativo el espacio de discreción argumentativa judicial y asegurar efectivamente el resultado de política legislativa buscado.

En efecto, nada impide que eliminada la expresión "individualidad legal determinada", la Corte Suprema siga sosteniendo que la existencia de multiplicidad de personas jurídicas equivalga a multiplicidad de empresas para efectos laborales colectivos, atendido diversos argumentos jurídicos de uso corriente, por ejemplo, que la personalidad jurídica está implícita en el concepto reducido, que no pueden existir obligaciones jurídicas sin un sustrato que la soporte, que la personalidad jurídica es un principio general para todo el derecho, etcétera.

En este punto, es especialmente relevante recordar, como ya se explicó, que la Corte Suprema exhibe una clara diferencia argumentativa ante el mismo problema del empleador aparente, según se trate de derechos individuales o colectivos. De ese modo, debe asumirse como máxima en este punto, a nuestro juicio, el alto riesgo que la o las modificaciones normativas que se realicen sean ineficaces, en cuanto no logren el objetivo de política laboral buscado, atendido el alto grado de discreción argumentativa con la que se mueve en ámbitos laborales la Corte Suprema y su hostil recepción al fenómeno colectivo en materia de derechos de los trabajadores ${ }^{29}$.

racionalidad jurídico política, porque buscaba solucionar el problema del empleador aparente dentro de un ámbito equivocado, como era el de las relaciones triangulares de trabajo. En efecto, esta propuesta considerada necesaria para el ámbito general de la legislación laboral, no parecía razonable dentro de un proyecto de alcance específico como era el de la subcontratación y suministro de empleo. Tanto por razones políticas (sólo solucionaría un porcentaje menor de los casos problemáticos de grupos de empresas), como jurídicas (reforzaría la idea de que en el resto de los casos, fuera del ámbito de esta específica ley, operará sin reparos el criticado concepto del artículo 3 del Código del Trabajo) la reforma al concepto de empresa en el proyecto de subcontratación es una buena idea en un lugar equivocado. Al final, la decisión del TC ha dejado fuera, por razones formales, esta norma de la ley No 20.123 sobre subcontratación.

${ }^{29}$ Un caso paradigmático de la hostilidad de la cuarta sala de la Corte Suprema con el fenómeno colectivo del trabajo, es la jurisprudencia que sostiene desde hace unos años sobre la interpretación del "reemplazo de trabajadores en huelga" del artículo 381 del Código del Trabajo. En contraposición a lo que la propia Organización Internacional del Trabajo le ha exigido a Chile, y a la interpretación que tanto la Dirección del Trabajo, como prácticamente toda la doctrina laboral han sostenido en la materia, véase CAAMAÑO y Ugarte Cataldo (2009). 
Cabe recordar, que la jurisprudencia laboral de la Corte Suprema no ha tenido problemas, ante reformas legales explícitas, en manejar discrecionalmente la argumentación jurídica, en defensa de sus posturas interpretativas previas a dichas reformas, frustrando significativamente la ratio legis de las reformas en cuestión ${ }^{30}$.

Se hace necesario, entonces, por la baja racionalidad formal y políticojurídica que exhiben estas propuestas, explorar otras opciones de modificaciones legales:

\section{c) Mantención del actual concepto de empresa con una norma adicional que descarte el elemento formal de persona jurídica como constitutivo por sí mismo de empresa laboral}

Esta propuesta admite dos versiones:

1. Versión simple o estrictamente negativa

La idea de esta propuesta es no forzar, dentro de las diversas posibles lecturas, la interpretación deseada por el legislador del concepto de empresa del artículo 3 del Código del Trabajo, sino que, más bien, establecer un veto negativo a la interpretación que no se desea:

"No constituyen empresa en los términos anteriores, la sola concurrencia de la condición de persona jurídica”

Esta propuesta exhibe, a nuestro juicio, un mayor nivel de racionalidad jurídico-político que las propuestas anteriores, en cuanto no confunde los problemas de grupos de empresas con el de empleador aparente, y apunta su esfuerzo legislativo con un enfoque preciso: resolver el uso de múltiples personas jurídicas por parte de un mismo empleador, que entorpezca o dificulte el ejercicio de derechos laborales colectivos.

Junto a lo anterior, cabe señalar, que esta propuesta presenta una mayor racionalidad jurídico-formal que las anteriores, porque no aumenta, sino que disminuye significativamente el ámbito de espacio argumentativo judicial.

Dicho de otro modo, se trata de una propuesta de reforma legal de menor vaguedad que las anteriores: no introduce al momento de fijar la interpretación deseada por el legislador, nuevos y potenciales elementos

\footnotetext{
${ }^{30}$ Pese a dos reformas legales, la de la ley $N^{0} 19.759$ de 2001 y la de la ley interpretativa $\mathrm{N}^{\mathrm{O}} 19.945$ de 2004, que buscaban aplicar el principio de continuidad en la empresa a las notarías, la Corte Suprema siguió sosteniendo por mucho tiempo en sus fallos que no se les aplicaba dicho principio, lo que obligó a proponer otra reforma legal, que por la vía de la ley $\mathrm{N}^{\circ} 20.510$, publicada el 28 de abril de 2011, intenta por tercera vez cambiar la jurisprudencia suprema.
} 
o conceptos susceptibles de ser interpretados, sino que, lisa y llanamente, veta la interpretación específica no deseada por el legislador. Reduce, de este modo, el espacio de discrecionalidad interpretativa.

Reduce el espacio de discreción interpretativa, pero no lo elimina, persistiendo un problema de vaguedad semántica relevante. Al solucionar el problema de modo negativo, señalando la interpretación no deseada, no asegura que se llegue a la solución deseada legislativamente, al existir un marco abierto para la decisión, pudiendo, una vez más, ponerse acento en cuestiones formales, tales como que esas razones sociales se dediquen a un mismo giro comercial, o cuestiones materiales irrelevantes, como que trabajen en actividades económicas complementarias o conexas.

\section{Versión compuesta o positiva}

Una segunda opción en este plano es mantener la actual redacción del concepto, pero se agrega una fórmula adicional que señale, ante el problema del empleador aparente, la interpretación deseada por el legislador en términos positivos: la identificación de empresa con empleador.

"Es una empresa para efectos laborales, la concurrencia de varias personas jurídicas, vinculadas por un mismo titular o propietario, que constituyan un sólo empleador”.

Esta propuesta mejora los niveles de racionalidad jurídico-formal que la versión simple o negativa, porque no sólo reduce el espacio interpretativo de la decisión judicial sino que da un paso más allá en términos de recorte de la vaguedad: simplemente cierra el espacio interpretativo al señalar la única interpretación deseada por el legislador frente al problema del empleador aparente, exigiendo de modo positivo que considere en la interpretación del artículo 3 la condición de empleador.

Esta propuesta presenta la mejor combinación de racionalidad jurídico-política, porque tiene claro el problema al que apunta la ratio legis: la concurrencia simultánea de múltiples personas jurídicas y de un sólo empleador, con racionalidad jurídico-formal, porque señala una solución específica y no ambigua para la interpretación normativa: la de vincular empresa con empleador.

En ese sentido, esta propuesta no genera un problema de vaguedad semántica, al modo de las propuestas anteriores, en cuanto no agrega un concepto potencialmente complejo o novedoso a la interpretación del artículo 3 del Código del Trabajo, sino que utiliza como elemento central de interpretación la idea consolidada en nuestro medio jurídico de empleador.

Cabe señalar en esta materia, por último, que las propuestas de reforma legal de las aquí analizadas o cualesquiera otras análogas, tienen 
un evidente déficit de racionalidad jurídico-pragmática al que es preciso poner especial atención. Lo anterior, atendida la alta posibilidad de que los objetivos políticos legislativos buscados terminen siendo frustrados por el problema específico del órgano estatal encargado de resolver el problema del empleador aparente aplicando la normativa legal modificada.

Dicho de otro modo, tiene poco sentido legislativo efectuar una reforma de la norma del artículo 3 del Código del Trabajo para resolver el problema del empleador aparente en materia de derechos colectivos del trabajo, si dicha solución, dotada de un objetivo político-jurídico preciso y sin problemas de vaguedad interpretativa, no se hace cargo del problema acerca de quién debe aplicar dicha normativa de modo razonablemente eficiente. De no hacerse cargo de este problema, existen altas posibilidades que la nueva normativa termine siendo inútil por falta de órgano público que la aplique, como ocurriría, por ejemplo, si los tribunales decidieran que la Inspección del Trabajo carece de competencia para aplicar el concepto de empresa reformada.

Atendido lo anterior, es que es imprescindible que cualquiera sea la alternativa de reforma que se elija, se aborde como propuesta complementaria necesaria la identificación del órgano encargado de su aplicación. Y como el problema que se busca resolver es el del empleador aparente en el ejercicio de derechos laborales colectivos, las posibles soluciones pasan por fijar la oportunidad y el órgano encargado de decidir el punto.

Ahí, y sin entrar en detalle en este punto, cabe señalar que las opciones no son muchas: por una parte, otorgarle expresamente esa competencia a la Inspección del Trabajo, por ejemplo, en el momento de la objeción de legalidad, o entender esa cuestión como de competencia exclusiva de los tribunales del trabajo. Ambas propuestas solucionan, una más que otra, el eterno problema del recurso de protección por incompetencia del Inspector del Trabajo.

\section{Conclusiones}

De las líneas anteriores es posible efectuar las siguientes consideraciones a modo conclusivo:

1. El núcleo del problema englobado bajo la expresión "del concepto de empresa", tiene relación con la inadecuada solución judicial al problema de la tensión entre la pluralidad jurídica en una entidad red con la noción unitaria de empleador en el ejercicio de los derechos laborales, pero particularmente en el ámbito de los derechos colectivos del trabajo. El problema se suscita, en rigor, por la falta de coherencia de la jurisprudencia judicial, en especial, 
de la Corte Suprema, en la aplicación del principio de primacía de la realidad.

2. En nuestro país, cuando se ha planteado judicialmente el problema del empleador aparente, entendido como uso de una pluralidad jurídica (multiplicidad de razones sociales) que corresponde a un sólo empleador, y que afecta el ejercicio de derechos laborales individuales, la jurisprudencia ha actuado levantado el velo corporativo, sosteniendo sus fallos en dos ideas combinadas: la unidad económica y la aplicación del principio de primacía de la realidad.

3. Se debería esperar que la situación del empleador aparente cuando se trata del ejercicio de los derechos colectivos, especialmente el derecho a la sindicación y la negociación colectiva, hubiera sido resuelta del mismo modo que la de los derechos individuales, esto es, que la jurisprudencia judicial procediera a levantar el velo corporativo en aplicación del principio de primacía de la realidad.

Sin embargo, ello no ha sido así. Un tipo de jurisprudencia que aquí llamamos formalista, que incluye fallos de la Corte Suprema ha resuelto el problema de la tensión entre la multiplicidad de personas jurídicas (razones sociales), y la existencia de una sola estructura de mando y subordinación (un empleador), a favor de las primeras, validando la práctica de que la división societal se traduzca en una seria afectación de los derechos colectivos del trabajo.

4. En rigor, como ya explicamos, el centro del debate legal aquí analizado corresponde al inadecuado trato que la jurisprudencia formalista viene dando al problema del uso fraudulento de la personalidad jurídica en materia de derechos laborales colectivos, y que hemos denominado el problema del empleador aparente. Todo fundado en una peculiar interpretación del concepto de empresa previsto en el artículo 3 del Código del Trabajo, que pone acento exclusivo en la expresión "identidad legal determinada".

Salvo fallos excepcionales, y a falta de expectativas reales de cambio jurisprudencial del problema del empleador aparente en materia colectiva, una opción viable a corto plazo corresponde a la de una modificación legal al artículo 3 del Código del Trabajo.

5. Una reforma legal debe tener objetivo claros y precisos (racionalidad jurídico-política), debe redactarse de modo que se reduzcan los problemas de vaguedad (racionalidad jurídico-formal), y debe lograrse efectivamente el resultado buscado por la ratio legis $\mathrm{u}$ objetivo del legislador (racionalidad jurídico-pragmática).

La opción que aparece con la mejor evaluación desde las distintas racionalidades legislativas analizadas, corresponde a la de mantener la actual redacción del concepto de empresa, pero agregando 
una fórmula adicional que señale, ante el problema del empleador aparente, la interpretación deseada por el legislador en términos positivos: la identificación de empresa con empleador.

"Es una empresa para efectos laborales, la concurrencia de varias personas jurídicas, vinculadas por un mismo titular o propietario, que constituyan un sólo empleador".

Esta propuesta tiene un alto nivel de racionalidad jurídico-formal porque no sólo reduce el espacio interpretativo de la decisión judicial sino que cierra el espacio interpretativo al señalar el elemento positivo que debe ser considerado en la interpretación del artículo 3 del Código del Trabajo, como es la condición de empleador.

En ese sentido esta propuesta presenta la mejor combinación de racionalidad jurídico-política -tiene claro el problema al que apunta la ratio legis: la concurrencia simultánea de múltiples personas jurídicas y de un sólo empleador-, con racionalidad jurídico-formal -señala una solución específica y no ambigua- la de vincular empresa con empleador.

6. Cabe señalar en esta materia, por último, que las propuestas de reforma legal de las aquí analizadas o cualesquiera otras análogas, tienen un evidente déficit de racionalidad jurídico-pragmática a la que es preciso poner especial atención. Lo anterior, atendida la alta posibilidad de que los objetivos político-legislativos buscados terminen siendo frustrados por el problema especifico del órgano estatal encargado de resolver el problema del empleador aparente aplicando la normativa legal modificada.

En ese sentido, existen dos vías posibles para resolver este problema: o radicar la competencia en la Inspección del Trabajo, y para evitar el tradicional debate sobre su competencia, sería necesario reconocerle en forma expresa en el artículo 331 del Código del Trabajo esta facultad, o radicar la competencia exclusivamente en los tribunales de justicia, mediante una gestión declarativa o de mera certeza acerca de la aplicación del concepto de empresa establecida en el artículo 3 del Código del Trabajo, y, en particular, de estar o no la empresa en la situación prevista por la modificación que aquí hemos propuesto.

En fin, y en cualquiera caso, de intentarse la vía judicial como órgano competente es especialmente importante que se considere el carácter temporal y urgente de la negociación colectiva, debiendo establecer una gestión judicial que asegure total rapidez y efectividad en la protección de los derechos colectivos involucrados 


\section{Bibliografía CITADA}

Artiles, Antonio Martín (1995). Flexibilidad y relaciones laborales: estrategias empresariales y acción sindical. Madrid: Consejo Económico y Social de España.

BAz Rodríguez, Jesús (2002). Las relaciones de trabajo en la empresa de grupo. Granada: Comares.

Boldó, Carmen (2000). Levantamiento del velo y persona jurídica en el derecho privado español. Navarra: Aranzadi.

CAamaño, Eduardo y José Luis Ugarte (2009). Libertad Sindical: un enfoque crítico, Santiago: LegalPublishing.

Calsamiglia, Albert (1999). "Justicia, eficiencia y optimo de la legislación”. Revista Documentación Administrativa, $\mathrm{N}^{\circ}$ 218. Madrid.

Dobson, Juan (1985). El abuso de la personalidad jurídica en el derecho privado. Buenos Aires: Depalma.

Hierrenzuelo, Ricardo, Pedro NúÑEz (2003). Responsabilidad solidaria en el contrato de trabajo. Buenos Aires: Hammurabi.

ItURRALDE, Victoria (1989). Lenguaje Legal y Sistema Jurídico, Madrid: Tecnos.

López Díaz, Patricia (2003). La doctrina del levantamiento del velo y la instrumentalización de la personalidad jurídica. Santiago: LexisNexis.

López Díaz, Patricia (2011). "La doctrina del levantamiento del velo en la jurisprudencia civil chilena". Revista Chilena de la Empresa Universidad Adolfo Ibáñez, $\mathrm{N}^{\circ}$ 25, Santiago. Enero-marzo.

Pérez de los Cobos, Francisco (1998). "El ‘desvelo’ de los grupos de empresas”. Revista Aranzadi Social, № 5 . Madrid.

Rojas, Irene, Aylwin, Andrés (2005). Los grupos de empresas en el Derecho del Trabajo. Santiago: LexisNexis.

TERradillos, Edurne (2000a). La representación colectiva de los trabajadores en los grupos de empresas. Granada: Colección Estudios Comares.

TERRADILlos, Edurne (2000b). Los grupos de empresa ante la jurisprudencia española. Madrid: Tirant lo Blanch.

Ugarte CATAldo, José Luis (2001). "La reforma laboral de la ley 19.759: luces y sombras". Revista Laboral Chilena, $\mathrm{N}^{\mathrm{0}}$ 11. Santiago, marzo.

UGarte Vial, Jorge (2012). "Fundamentos y acciones para la aplicación del levantamiento del velo en Chile". Revista Chilena de Derecho, vol. 39, № 3. Santiago.

Varela Fleckenstein, Andrés (2011). "La doctrina del levantamiento del velo en la jurisprudencia nacional”, en María Fernanda VÁsquez Palma (dir.). Estudios de derecho comercial. Primeras jornadas de derecho comercial 2010. Santiago: AbeledoPerrot. 